\title{
Alejandro Sawa en una necrológica desconocida de Arturo Vinardell ${ }^{*}$
}

\author{
Alejandro Sawa in an unkown obituary by Arturo Vinardell \\ Sergio Constán Valverde \\ Universidad de Las Palmas de Gran Canaria, Las Palmas de Gran Canaria, España. \\ Correo electrónico: sergio.constan@ulpgc.es
}

Se exhuma una crónica necrológica sobre el escritor Alejandro Sawa, de la que hasta ahora no parecía tenerse noticia. Firmada en París bajo el seudónimo de "Darwin” (Arturo Vinardell Roig), sus líneas constituyen un testimonio de primera mano para el mejor conocimiento biográfico del célebre bohemio. Del análisis que este trabajo ofrece se desprenden nuevas claves y lecturas sobre su etapa parisina.

Palabras clave: Alejandro Sawa, Arturo Vinardell Roig, Bohemia española en París, Prensa periódica canaria.

An obituary about the writer Alejandro Sawa is exhumed, of which nothing seemed to be known about. Signed in Paris under the pseudonym "Darwin" (Arturo Vinardell Roig), the document is a firsthand witness to the best biographical knowledge of the famous bohemian. New clues and readings on his Parisian stage are offered starting from the analysis that this work provides.

Key words: Alejandro Sawa, Arturo Vinardell Roig, Spanish Bohemia in Paris, Canary Islands' periodicals.

Este trabajo es resultado del proyecto de investigación de la Universidad de Las Palmas de Gran Canaria titulado Representaciones literarias en la prensa periódica canaria del siglo XIX (ULPGC11-14), dirigido por la doctora Victoria Galván González. 
El 6 de abril de 1909, un mes y tres días después del fallecimiento de Alejandro Sawa, el Diario de Tenerife publicó una página necrológica sobre el sevillano, firmada con el seudónimo de "Darwin". Inserta en la sección "Crónica de París", llevaba por título "Los grandes bohemios. Alejandro Sawa", y aparecía fechada en la capital francesa, en el mes de marzo ${ }^{1}$. Entre la cada vez más abundante bibliografía sobre Alejandro Sawa no hay constancia de este documento, portador de nuevas claves sobre el periplo biográfico del escritor en sus años parisienses. La crónica se suma a las numerosas necrológicas reproducidas en periódicos y revistas en los días inmediatamente posteriores al deceso del malogrado bohemio; alrededor de una veintena de textos que, atendiendo al listado ofrecido por Amelina Correa Ramón (2008: 296), vieron la luz en ABC, Diario Universal, España Nueva, El Globo, Heraldo de Madrid, El Imparcial, El Liberal, El Mundo, Nuevo Mundo, El País y Prometeo.

"Darwin" fue el seudónimo utilizado por el periodista, publicista y escritor catalán Arturo Vinardell Roig (1852 -1937), quien conoció y trató asiduamente a Sawa en la casa editorial Garnier, donde coincidieron como redactores del Diccionario enciclopédico de la lengua castellana. Nacido en La Bisbal d’Empordà, provincia de Gerona, Vinardell se inició en el periodismo colaborando en numerosos medios gerundenses y barceloneses, algunos de los cuales fundó o dirigió. De entre los de la capital catalana cabría mencionar La Campana de Gràcia, Catalunya, Gaceta de Cataluña, La Humanidad, El Liberal, Las Noticias, La Publicidad, La Renaxensa o La Vanguardia. Su ideología política quedó pronto fijada en el republicanismo federal, de lo cual dio buena cuenta su temprana tarea en la dirección de periódicos como El Progreso Juvenil (1868) y La Provincia (1872). En 1886 el nombre de Vinardell saltó a la palestra política y periodística por un sonado delito de injurias a la corona, después de que, bajo su dirección, El Demócrata reprodujera la durísima diatriba titulada “¡Pobre Rey!”. El texto, que había aparecido antes en El Baluarte de Sevilla con la firma de José Rodríguez La Orden, arremetía duramente contra la monarquía española, centrando sus embates en el recién nacido Alfonso XIII. El bisbalense lo publicó en sus páginas el 3 de junio de 1886, en la primera columna de la primera plana. Si periódicos como El Pueblo Balear, de Palma de Mallorca, o el menorquín El Liberal habían reproducido también aquellas líneas antimonárquicas antes que El Demócrata y sin ninguna consecuencia penal para sus directores, no sucedería lo mismo con Vinardell. Absuelto primeramente por la Audiencia de Gerona, el Tribunal Supremo lo condenó a diez años y un día de prisión mayor. Por esa razón el periodista huye a Francia y se instala en París. Más de cuarenta años vivirá el catalán en la capital francesa y, con la excepción de un regreso puntual en 1892, con motivo de una amnistía, no reanudará su vida en su ciudad natal hasta 1925, ocupando el puesto de conservador de la Biblioteca Municipal. Falleció en 1937, después de haber sufrido un atropello accidental en la vía pública, un año antes ${ }^{2}$.

La línea con que quedó erróneamente datada — "París, marzo de 1900"- obedece evidentemente a un desajuste tipográfico. Al menos en un rotativo más, en La Región Extremeña, se publicaron estas líneas, un día después de haberlo hecho el diario canario. Es probable que conociera alguna otra reproducción, pero no he logrado encontrarla. Al final de este trabajo se reproduce el texto de forma íntegra.

2 Para todo lo relacionado con los motivos del exilio de Vinardell, véase Josep Clara (1987: 75-79). Aunque es en este trabajo donde se señala 1892 como el año de ese regreso aislado de Vinardell a su tierra, aprovechando una amnistía, hay que suponer que hubo algunos otros. Así, en la sección de noticias del gerundense La Lucha del 17 de septiembre de 1902 se da la bienvenida a "nuestro querido compañero el ilustrado escritor y paisano don Arturo Vinardell y Roig 
La labor periodística de Vinardell en tierras galas fue ingente. Colaboró en el Correo de París, fundó las revistas Centre Català: Catalunya-París y En avant... quand même! (editada en francés y en español), y dirigió el Paris-Quichotte, el número especial con el que se conmemoraría el cuadringentésimo aniversario de la publicación del Quijote. Entre los años 1887 y 1890 redactó casi en solitario una hoja autógrafa diaria: El Corresponsal de París. Denise Fischer Hubert (1994) ha rastreado la huella dejada por Vinardell en periódicos de lengua francesa, donde escribió encendidos textos en aquel idioma; un listado conformado por L'Action, L'Aurore, La Cocarde, Les Droits de l'Homme, L'Echo de Paris, L'Estafette, L'Européen, L'Evénement, Le Matin, La Nouvelle Revue, La Patrie o La Revue Diplomatique. Aquellas incansables apariciones en la prensa gala perseguían acabar con los prejuicios de los franceses sobre España, con su extensa cadena de tópicos infundados o de errores inadmisiblemente perpetuados. En España en París el propio Vinardell dejó claro cuál era la batalla que quería dar en Francia con sus artículos y sus cartas abiertas: defender "la causa santa y el buen nombre de nuestra patria" (1902: XI). Enrique Gómez Carrillo, prologuista de este volumen, explicaba tal incansable y quijotesca beligerancia del catalán en los siguientes términos: "Cada vez que un periodista francés se muestra injusto para con España, allí está Vinardell, siempre despierto, para contestarle. [...] ha defendido el buen nombre de su patria grande, y también el de Cataluña, su patria chica." (id.: X). Desde la capital francesa, el infatigable periodista también envió crónicas a distintos medios españoles ${ }^{3}$.

En cuanto a los libros de Arturo Vinardell, hay que decir que fueron escasos. Más allá del citado España en París, vertió su pensamiento político en El partido republicano en España: impresiones políticas (Barcelona, I. López, ca. 1895). Cultivó la poesía, casi siempre al calor de premios en certámenes poéticos, loas y homenajes públicos; versos editados, a menudo, en folletos o a través de la colección de alguna revista (valgan como botón de muestra A los hijos del arte. Un recuerdo y una lágrima. Odas escritas por Arturo Vinardell Roig, Gerona, Establecimiento tipográfico de Paciano Torres, 1873, o Poesies, en el cuaderno 355 de la colección Lectura popular, Biblioteca d'autors catalans, de la revista gráfica La Ilustració Catalana). A sus Hores tràgiques i anecdòtiques de la guerra (Girona, Dalman Carles

[sic], que en unión de su bella hija ha llegado de París". Por otro lado, es frecuente encontrar en la prensa el nombre del escritor como acaba de citarse, con la conjunción entre apellidos, o bien unidos por guion. Opto por emplear la firma aparecida en la mayor parte de sus artículos y en todos sus libros escritos en español: Arturo Vinardell Roig. Así figuraba también en sus tarjetas de visita, como prueba la que se conserva en la Casa Museo Pérez Galdós, en Las Palmas de Gran Canaria.

\footnotetext{
Vinardell fundó en 1906 el Centre de Publicité Latin-Américain, que desde París surtía regularmente crónicas y artículos a la prensa española e hispanoamericana. En España su firma pudo leerse en periódicos madrileños como $E l$ Día o El Globo, y en catalanes como La Lucha o Las Circunstancias, además de en el citado La Región Extremeña; entre las cabeceras canarias citaré algunas como Diario de Tenerife (donde aparece su nota necrológica sobre Sawa), El Imparcial y, de forma muy profusa, La Opinión. Llama la atención esta intensa presencia como colaborador en la prensa de las islas, algo que podría explicarse por su estrecha relación personal y profesional con canarios residentes en la capital gala como Elías Zerolo o Nicolás Estévanez, a quienes más adelante habré de referirme. Sus artículos, firmados indistintamente con seudónimo - Darwin - o con su nombre, se insertaban en la ya señalada sección “Crónica de París" (título que conoció alguna variante puntual, como la de "Parisiana”), alternando con los de otros cronistas establecidos en París: Arturo del Villar, Xavier de Carvalho, E. Paul Armarza o Rafael Mesa y López. Estas colaboraciones de Vinardell en los rotativos canarios se extienden a través de las dos primeras décadas del nuevo siglo; en el XIX solo he podido encontrar una crónica suya ("El campo de Marte. Ojeada Histórica", en el Diario de Tenerife, 19-X-1899). Tampoco he hallado, en la prensa decimonónica insular, eco alguno del delito periodístico que supuso el exilio de Vinardell.
} 
Pla, 1930) pueden sumarse dos libros inéditos sobre la Primera Guerra Mundial, según se recoge en algunas enciclopedias. En 1902 se hizo cargo de la antología Los mejores cuentos de los mejores autores españoles contemporáneos (París, Vda. de C. Bouret), donde juntó a escritores de la vieja generación - Galdós, Echegaray o Pardo Bazán, entre otros- con voces nuevas como las de Joaquín Dicenta, Manuel Machado o Gómez Carrillo4.

Este fue el tipo de firme intelectual y sólido hombre de letras con que se cruzó Sawa en su periplo parisino, el mismo que acabaría dedicándole la página necrológica objeto del presente estudio. Vinardell comienza su texto reconociendo sin ambages el signo de una mala relación personal con Sawa: "los malísimos recuerdos que dejó en mí al desaparecer súbitamente de París”, admite, si bien quiere dejar igualmente patente su sincero sentimiento de tristeza por la muerte del bohemio. La noticia del óbito, que le ha llegado "a los pocos meses de conocer su ceguera"”, produce en Vinardell el suficiente impacto como para olvidar por un momento las malas experiencias vividas con el andaluz, y escribir así en memoria de un hombre a quien había tratado con intensidad entre 1889 y 1896, los años parisinos de aquel. Entre los recuerdos negativos que Vinardell quiere desterrar, hay uno al que alude someramente, y que se corresponde con lo que debió obedecer a un "momento de aberración mental" por parte de Sawa; alguna fea y disparatada acción que el comentarista tacha de ingrata por haber sido dirigida sobre quien, desinteresadamente y en nombre de la amistad, lo había ayudado en no pocas ocasiones. Conviene antes saber que Vinardell, según puede colegirse del testimonio de terceros, hubo de poseer un carácter algo más que serio, y desde luego poco dado a las informalidades. En La bohemia española en París a fines del siglo pasado, Isidoro López Lapuya se refiere al catalán, en repetidas ocasiones, como "hombre de mal genio". Por su parte, Gómez Carrillo lo recuerda imponiéndose entre el griterío de sus compañeros de la redacción del Diccionario con "su elocuencia, exigiendo seriedad y atención”" No ha sido posible dar con el desagradable incidente aquí aludido y que acabaría de

$4 \quad$ La dedicación de Arturo Vinardell como traductor no debe pasarse por alto, como se desprende del muy completo rastreo realizado por el citado Fischer Hubert. Volcó al francés los dramas en lengua catalana Mar i cel y La festa del blat, de Ángel Guimerá. Es probable que también tradujera La pecadora, pues existe una carta en el fondo Ángel Guimerá en la que el dramaturgo autoriza a Vinardell la versión francesa de esta pieza (véase el inventario elaborado por Ramon Molins, Fons d’Àngel Guimerà. Inventari, Biblioteca de Catalunya, Barcelona, 2003, p. 48); además se conserva también en este fondo la propuesta de candidatura del autor al Premio Nobel por parte de la Reial Acadèmia de Bones Lletres, donde tal traducción se da por realizada (puede leerse íntegramente en el libro de Enric Gallén y Dan Nosell, Guimerà i el Premi Nobel. Història d'una candidatura, p. 86). Desde París, Vinardell se ofreció a Galdós para traducir Electra al francés, como prueban dos cartas de febrero de 1901, hoy en la casa museo del canario. Al castellano tradujo obras literarias francesas (Cartas amatorias de Mirabeau, Obras completas de Xavier de Maistre y Zizi, historia de un gorrión de París, contada por él mismo, de Henri Demesse), así como algunos títulos en el marco de otras disciplinas (Tartamudez y otros defectos de pronunciación, de Arthur Chervin, La práctica de la homeopatía simplificada, de Alexis Espanet y Vichy y sus aguas minerales; de esta última, anunciada en otro libro de Vinardell, no he hallado rastro de ningún ejemplar). Igualmente colaboró, bien como traductor, bien como redactor, en publicaciones médicas tales como La Semaine Médicale, La Revue des Alcaloïdes, Revue Critique de Médecine et de Chirurgie, Moniteur Thérapeutique o Revue de Technique Médicale. A propósito de su ingente tarea traductora, López Lapuya (2001: 78) afirma que en la oficina de la redacción del Diccionario enciclopédico Vinardell "[...] faltaba mucho, concediendo una inteligente preferencia a sus traducciones para boticarios y médicos".

5 Vinardell tardó en saber de la ceguera de Sawa, producida en 1906 según especialistas como Phillips o Correa Ramón; Iris M. Zavala, por su parte, no descarta incluso el año 1905.

6 “A guisa de prólogo”, en España en París, op., cit., p. VIII. 
mostrar la verdadera encrucijada de sentimientos desde los que escribe Vinardell. Ni siquiera hay constancia de él en las memorias de Lapuya, donde sí se ofrece al menos alguna muestra de lo que debieron ser los comportamientos fuera de lugar de Sawa, precisamente hacia algún que otro compañero del resto de la redacción: Manuel González de la Rosa, el propio López Lapuya, Emilio Prieto y su joven ayudante Vallejo, Santiago Romojara y Miguel de Toro y Gómez, todos ellos bajo la dirección de Elías Zerolo7.

Entre esas reacciones temerarias del incorregible Alejandro, se halla una que viene precedida de una pesada broma suya a Romojara, y cuyo desenlace pretexta un discurso de González de la Rosa sobre la importancia del amor al prójimo. Nuestro bohemio, que nunca simpatizó con el erudito peruano -otrora sacerdote-, no soportó aquel aire de homilía que iban adquiriendo sus palabras: a las demenciales imprecaciones de Sawa siguieron varios tiros suyos con un revólver que terminaría lanzando por el aire, entre el pánico de los presentes. Este no es más que un conocido ejemplo de "momento de aberración mental" a los que el volátil temperamento de Sawa fue dado; y si bien el repertorio de los mismos se intuye tan amplio como variado, no hay que descartar que a algo parecido pudiera estar refiriéndose Arturo Vinardell. Representa, en cualquier caso, el Sawa que quiere olvidar para centrarse en el "escritor de talento" que fue capaz de dejar su impronta en París, algo solo reservado, en su opinión, a los “audaces o a los escogidos”. Estos son los primeros elogios que el cronista vuelca sobre Sawa, y que le valen para acabar de separar de su memoria determinadas experiencias de infausto recuerdo.

Una vez fijadas las consideraciones sobre lo puramente personal, Vinardell precisa a continuación el momento exacto en el que Sawa llegó a la capital del Sena para vivir allí durante siete años: "vino Sawa a París cuando acababa de cerrar sus puertas la brillante Exposición universal de 1889”. Se trata de algo que podría arrojar luz sobre una de las incógnitas biográficas del autor de Crimen legal, cual es el hecho de que "no se conoce con exactitud la fecha del segundo viaje de Alejandro Sawa a París”. Phillips (1976: 61) lo había situado “hacia 1889 o 1890”, mientras que Correa Ramón (2008: 157) apunta el año 1889, dando por segura la presencia del sevillano en la Exposición. Si la aseveración del cronista es cierta, Sawa se instaló en su ciudad fetiche no antes de noviembre de aquel año, pues fue el 31 de octubre cuando se clausuró el gran evento. Vinardell parece mostrarse seguro al respecto, pues en una nota a pie de página — sobre la que necesariamente volveré más adelante- afirma de nuevo que "Sawa llegó a París a fines de 1889".

Estos nombres, junto con los de Arturo Vinardell y Alejandro Sawa, integran el primer elenco de redactores del Diccionario enciclopédico; seguidamente se incorporaría, en palabras de López Lapuya, "la plana mayor diccionaresca”: Luis Bonafoux, Ricardo Fuente, Enrique Gómez Carrillo, Emiliano Isaza, Manuel Picouto, Francisco Sarmiento y un supuesto aristócrata de apellido López (recomendación del embajador de España en París, el canario Fernando León y Castillo, a su paisano Zerolo). Más adelante se integrarían Constantino Román Salamero y Javier Tiscar, y ya en las futuras actualizaciones del diccionario colaborarán nombres como los hermanos Machado (Fisher Hubert anota también el de Amado Nervo). Joaquín Dicenta, en el prólogo a De un periodista (1897), de Ricardo Fuente, incluye como redactor del diccionario a Nicolás Estévanez, muy relacionado con la casa Garnier (publicó en ella varios libros y numerosas traducciones).

$8 \quad$ Es afirmación de Correa Ramón (2008: 157), quien refiere un viaje anterior, de unas seis semanas, basándose en lo narrado por Dicenta en su novela en clave Encarnación (1913). Esta primera incursión de Sawa en París, generadora de la historia del beso huguesco, debió realizarse antes de mayo de 1885, con Victor Hugo aún en vida. 
De ser correcto el dato de Vinardell se pondría en cuestión la veracidad de unas palabras del propio Sawa publicadas en La Lucha el 16 de julio de 1904, y que han conformado precisamente la base para suponerlo en París entre mayo y octubre de 1889, durante l'Exposition Universelle:

Yo tengo grabado en los sesos, con irradiaciones que me llegan hasta el corazón, el recuerdo de aquel 14 de julio de 1889 con que París celebró el primer centenario de la toma de la Bastilla. La grandiosa Exposición, que era el número más brillante del espléndido programa de festejos, estaba en todo su auge y en aquellos días París podía proclamarse, con más razón que nunca, la gran metrópoli del mundo. Los preparativos para la celebración de la hermosa fiesta revolucionaria, habían comenzado con quince días de anticipación y al amanecer del día histórico, París ofreció uno de los espectáculos más suntuosos que pueden soñarse ${ }^{9}$.

¿Mentía Sawa, en su legendaria propensión a construir, de sí mismo y para la historia, un personaje extraordinario? ¿Lo traicionaba su memoria o acaso lo hacía él mismo, usando el recuerdo de cualquier otra ostentosa fiesta nacional de la que fuera testigo en los años siguientes? ¿Pudo más, al fin, la vanidad del yo estuve allí? La firmeza de la afirmación de Vinardell es compatible, no obstante, con lo que representaría una tercera posibilidad: que Sawa hubiese realizado su segundo viaje a París en el verano de 1889 para visitar la Exposición Universal, y que acaso este le sirviera como fase preparatoria de su tercera y definitiva estancia en la ciudad, ahora sí, a finales de ese año.

Como quiera que fuera, el periodista parece insistir en su afirmación, al apuntar que Sawa solo alcanzó a ver las dos principales joyas arquitectónicas que sobrevivieron a la Exposición: el Palacio de las máquinas y la Torre Eiffel. Ese mismo hecho lo aprovecha para continuar ahondando en la psicología del bohemio: "Si otra cosa no hubiese tenido París, esto solo era ya bastante para atraer a Sawa, que nunca supo profesar otro culto que el culto a lo grandioso y a lo sublime".

Es entonces cuando Vinardell concreta el contexto en el que conoció al sevillano, ya adelantado aquí: la redacción del Diccionario enciclopédico de la editorial Garnier. Así le ocurrió con tantos otros, según afirma, aunque solo nombra a modo de ejemplo al común amigo Enrique Gómez Carrillo. Seguidamente enumera las razones por las que el bohemio "salió a escape” de aquel lugar ${ }^{10}$, a saber: más elevadas aspiraciones que las del resto de los redactores; su independencia de espíritu; la incompatibilidad entre un carácter caótico y un tipo de trabajo que requiere método; su carencia absoluta de disciplina, indispensable para afrontar horarios, tareas monótonas y aburridas. Porque para Vinardell, en definitiva, "Sawa sentíase con fuerzas para volar por otras regiones y abarcar otros horizontes", lo cual no podía avenirse con los objetivos de aquel local de la Avenue du Maine. Una vez abandonados sus compañeros enciclopedistas, refiere el catalán, dio comienzo la personal conquista de París, activándose en él su más sublime alma de bohemio.

“El 14 de julio”, en La Lucha (16-VII-1904), apud Alejandro Sawa (2008: 354).

10 Según el testimonio de López Lapuya, Sawa no volvió más a la redacción del Diccionario tras el referido incidente del revólver, con González de la Rosa como detonante. 
Llega de inmediato el párrafo con el que el comentarista cincela su particular busto de Alejandro Sawa. Para ello, y a tenor del contenido, es probable que Vinardell se apoyara en las afortunadas páginas que Luis París dedicara a Sawa en su libro Gente nueva. El célebre volumen del reputado crítico literario, aunque editado hacia 1888 , es decir, con Vinardell ya en el exilio, fue muy probablemente conocido por el periodista, atento siempre a la actualidad literaria de su país. De todos los retratos que Luis París dedicó a los "hijos del fin de siglo", el del andaluz era uno de los más extensos al tiempo que elogiosos; la lucidez de esas páginas sobre un Sawa que aún no sumaba su fundamental experiencia parisina, supusieron buena parte de la base sobre la que muchos comentaristas y exégetas del sevillano ensayarían sus propios retratos del bohemio. Como ha señalado Correa Ramón, Luis París recogió en su capítulo sobre Sawa algunos de sus rasgos más definitorios: "su radical apasionamiento, su total fascinación por la literatura $[\ldots]$, un espíritu bohemio e inconformista, o ese romanticismo constitutivo que lo permearía siempre" (2008: 66). La semblanza de Vinardell, que no deja de participar de estas cuatro dimensiones de la personalidad sawiana, encuentra en las siguientes palabras el momento de mayor condensación retratística: “De regular estatura, arrogante en sus maneras sin ser altivo, con su poblada barba negra de moruno aspecto, ostentando en su opulenta cabeza una abundosa melena semejando una cimera, era Sawa un tipo francamente español, simpático en extremo.” El recuerdo vívido del antiguo amigo parece acudir a la memoria de Vinardell, pero es entonces cuando se pisan lugares comunes sobre el físico de Alejandro Sawa, los mismos a los que tantos coetáneos recurrieron una y otra vez; por encima de todos ellos, lo tocante a la cabeza del escritor, desde la arábiga barba a la llamativa melena. Luis París se había referido a Sawa como un "joven de cabeza artística, melena romántica y barba árabe; tan genial en todo cuanto formaba su indumentaria, que constituía un tipo verdaderamente original” (1888: 103). Pero en este punto también pudo Vinardell tener presentes las palabras de alguien mucho más cercano a él, el citado Gómez Carrillo, cuando en unas tempranas líneas escribía:

Una cabeza sorprendente cuya fuerza de expresión hace pensar en aquellos moros españoles de la Reconquista, y cuya firmeza de rasgos habría inspirado a Teodoro de Banville —el miniaturista admirable - un camafeo delicioso. [...] la barba, negra y rizada, como la espléndida melena $(1892: 67)^{11}$.

No obstante, Vinardell sabe poner su nota original sobre la mitificada testa de Sawa al construir un acertado símil entre su melena y una cimera. Con tal adorno guerrero parece subrayarse el componente heroico e idealista de su portador, al remitirnos necesariamente a los caballeros medievales; pero se atiende también al otro polo del exotismo físico propio del sevillano - uno había sido el moruno, según se ha señalado ya-, y que fue el griego. Las cimeras valen también para aludir a

\footnotetext{
Otras referencias que, de la singular cabeza sawiana, Vinardell pudo conocer antes de su semblanza fueron las de “cabeza artística" (Antonio Palomero en El Nuevo País, 28-I-1899) o "bellísima cabeza morena, rizada, artística" (de nuevo Gómez Carrillo en La Vida Literaria, 4-II-1899 y en Sensaciones de París y de Madrid, París, Garnier Hermanos, 1900, p. 49). Es probable que alcanzara a leer algunas de las necrológicas que aparecieron desde el 3 de marzo de 1909, en las que la testa del bohemio también mereció comentario: "cabellera de romántico" (Luis Bello en El Mundo, 3-III-1909); “cabellera romántica” (José San Germán Ocaña en Nuevo Mundo, 8-III-1909); “cabeza artística y sarracena [...] digna aureola para un poeta” (Ramón Gómez de la Serna en Prometeo, 4-II-1909, aunque de aparición posterior a la muerte de Sawa).
} 
los hoplitas, tan vistosas en sus cascos como en los de ningún otro soldado. Sawa, descendiente de griegos, tuvo y cultivó siempre ese aire helénico del que su rostro fue principal protagonista. Como es sabido, no faltaron tampoco páginas con referencias a este punto, sobre las que acaso vino a poner el colofón Valle-Inclán en su gran esperpento: "Su cabeza rizada y ciega, de un gran carácter clásico-arcaico, recuerda los Hermes.” (1991: 48). Para atemperar el conocido carácter extranjerizante de Sawa, ese elegido y afectado afrancesamiento del que hacía gala, Vinardell deja clara su inequívoca españolidad, al tiempo que subraya su enorme simpatía. Lo hace antes de adentrarse en recuperar otra de las repetidas etiquetas sawianas: la extraordinaria semejanza física del bohemio con Alphonse Daudet. Para ello, el catalán vuelve a tirar de lecturas: "Alguien ha dicho - y es cierto- que Sawa tenía un asombroso parecido con Alphonse Daudet, con su cara de Cristo resucitado.” Al margen del propio Alejandro Sawa, que satisfizo una de sus aristas mitómanas emulando el rostro del autor de Nimes, uno de los primeros en propagar tal parecido facial pudo serlo el citado López Lapuya. Aunque su testimonio escrito no se publicó hasta el primer cuarto de siglo, hay que suponerlo extendiendo entre sus compatriotas de París la teoría de lo que es hacerse una cabeza, con el caso de Sawa como paradigma:

Hacerse una cabeza en París, es cortarse el pelo en forma original, o dejarlo crecer de manera rara, peinarse como nadie se peine, etc., etc. La cuestión es que la cabeza -y la cara con barba o sin ella - tenga un sello de individualidad no confundible con el vulgo. Claro está que a la cabeza acompaña el sombrero: y puestos en el camino de la originalidad, al tocado sigue la corbata, a esta la americana, que no es americana, ni guerrera, ni justaucorps ni nada más que lo ideado por el artista, el poeta, el novelista, en complicidad con algún hábil sastre.

Sawa se había hecho una cabeza; pero a la verdad, siempre me pareció inspirada en Alfonso Daudet: lo que mermaba la originalidad $(2001: 47)^{12}$.

En 1901 firmas como las de Gregorio Pérez Arroyo insisten en este punto: “parisién de melenas y sombrero a lo Daudet”, escribe sobre Sawa. Pero es tal vez un texto publicado dos años antes el que, por su importancia, se encargó de fijar sobre futuros articulistas y memorialistas tal asociación fisonómica entre las dos ilustres figuras; y el que, probablemente, mantuviera algún eco en la memoria de Vinardell. Me refiero a un conocido artículo de Claudio Frollo aparecido un día después del exitoso estreno de Los reyes en el destierro, adaptación de la novela de Daudet realizada por Alejandro Sawa. En él recuerda el autor el día en el que Sawa entró en la redacción con "un perfil muy parecido al de Daudet; gran melena, gran barba; gran sombrero napolitano y gran dejo francés, que aquí ha perdido, trocándolo por un gran dejo de amargura" ${ }^{13}$.

12 Buena prueba de esa labor de propagación oral por parte de Lapuya viene a darla, muchos años después, Francisco Pompey (1972: 87): “A este propósito, el periodista J. [sic] L. Lapuya —residente en París y amigo de Sawa- me decía que la cabeza de Sawa se destacaba entre las de los escritores y artistas por «su belleza griega» y que era más bella que la de Alfonso Daudet, el gran novelista." Por otro lado, resulta curioso cómo en El árbol de la ciencia, novela de 1911 en la que Baroja hace de Rafael Villasús un trasunto de Alejandro Sawa, el narrador afirma del catedrático Letamendi: "Se veía en él un hombre que se había hecho una cabeza, como dicen los franceses" (Pío Baroja 1982: 39).

13 El texto de Claudio Frollo compartía página con una encomiástica crónica teatral firmada por L. B., pero a diferencia de esta y de otras muchas, no venía a aplaudir el éxito del estreno; antes bien, aprovechaba la ocasión para algo de 
Las propias necrológicas publicadas desde el 3 de marzo de 1909 pudieron también llevar a Vinardell a repetir lo que, como señalo, fue siempre un motivo recurrente: Sawa como Daudet. Pendiente siempre el catalán de la actualidad literaria de su país, hay que imaginarlo leyendo con retraso los obituarios de los periódicos españoles, demorados por la distancia y por los imponderables del servicio postal, o entregados en mano merced a la última visita del compatriota de vuelta. Así, en el dedicado por El Liberal (3-III-1909), sin firma, se decía de Sawa: "Su barba hirsuta y su enmarañada melena placíanle porque le recordaban la cabeza de Daudet.” En la ya citada "Iconografía literaria" que José San Germán Ocaña le brinda en Nuevo Mundo (8-III-1909), se daba cuenta de "su rostro todo en el que redivivía gentílicamente Alfonso Daudet"14.

Con ese peculiar atractivo físico y con su propio talento Sawa supo granjearse la amistad de los intelectuales franceses. Sin embargo, la intimidad con algunas controvertidas figuras comprometieron, en opinión del cronista, su integridad moral. Es a estas alturas de la semblanza cuando Vinardell exhibe todo su más radical moralismo, afirmando directamente que tales compañías llevaron al escritor a "pervertirse en sus costumbres, y casi, casi a rebajarse". A la cabeza de ellas, la de Paul Verlaine, señalado casi como anatema en un retrato análogo al de aquellas célebres fotografías de Dornac (Paul Marsan), con el poeta maldito bebiendo ajenjo en el café François I, allá por 1892:

Amplio y elocuente en sus palabras, elegante en su decir y en sus maneras, vile yo muchas veces a la altura de Paul Verlaine, su ilustre y querido amigo a quien tuteaba, cuando este, en sus momentos de furor alcohólico, arrastraba el manto de armiño de la santa poesía por el subsuelo de ciertas tabernas a la moda o bajo las mesas del Café François, el punto de cita y sanedrín de toda la bohemia trashumante de aquel París intelectual, que había consagrado a Verlaine como su Dios y a Moreas [sic] como su profeta.

Como sabemos, Sawa había consolidado estrechas relaciones con escritores y artistas simbolistas, convirtiéndose en un asiduo de las cenas semanales organizadas por el fundador de La Plume, Léon Deschamps, en el café Soleil d'Or. En esa órbita decadentista y bohemia, que alcanzó también otros cafés como el d'Harcourt o el referido François I, el sevillano trató a Charles Morice, Gabriel Vicaire o al citado Jean Moréas, entre otras muchas figuras; pero fue sin duda Verlaine quien se erigiría en el centro de su desmedida idolatría. A tal "pléyade de jóvenes más o menos ilustres" que conformaban la corte del Pauvre Lelian dice Vinardell haberlos

mayor calado: reivindicar al bohemio en un momento en el que las enormes expectativas generadas por su talento habían empezado a transformarse en dudas, por mor de una inactividad que fue para muchos hija de la pereza. Sus líneas suponían directamente un aldabonazo al propio Sawa, una forma de espolear al escritor a fin de hacerlo reaccionar y devolverlo a su tarea creativa: "Sawa, que antes hizo mucho más, puede hacer más; es necesario que haga más...” (Claudio Frollo 1899).

14 Estos son solo algunos de los testimonios que recogen ese proceso mimético entre Daudet y Sawa, traídos aquí para calibrar el grado de aportación original en el texto de Vinardell. Sobre el parecido de Sawa con el autor de $L e$ nabab se continuará insistiendo, póstumamente, a lo largo de todo el resto del siglo XX: lo harán, entre otros, Rubén Darío (Autobiografía, 1913); Joaquín Dicenta (Encarnación, 1913); Manuel Machado, "Del Madrid lejano. Andaluces de origen griego. Sawa y la “peña” de El Colonial”, 1943); Pío Baroja ("Espectros de bohemios”, en Canciones del suburbio, 1944); Emilio Carrere ("Los espejos de Fornos”, La Libertad, 27-I-1933, "Elegía de los cafés románticos", ABC, 21-VII-1946 o "La casa de Alex Sawa”, Madrid, 20-X-1946); José Ortiz de Pinedo, Viejos retratos amigos (1949), o el citado Pompey (Recuerdos de un pintor que escribe, 1972). 
conocido, distinguiendo en ellos dos grupos: el de quienes continuaron con "aquella vida insípida de bacanal hedionda”, y el de quienes canalizaron talento y ambición para acabar entrando en política. De forma implícita — acaso por eliminaciónAlejandro Sawa parece quedar ubicado entre los primeros; a propósito del segundo elenco, Vinardell cita como caso representativo el de Pierre Baudin, amigo de Sawa durante sus años en París, que llegó a ocupar la cartera de Ministro de Obras Públicas entre 1899 y 1902, y la de Marina en $1913^{15}$.

La dura invectiva lanzada contra la vida bohemia alcanza su mayor intensidad en la metáfora ya indicada ("hedionda bacanal"), pero no se detiene ahí; antes bien, continúa al compararse el destino de Baudin con el de la mayoría de los antiguos compañeros de Sawa, esos que "se han estado royendo las uñas de pobreza o de fastidio, sin contar los que han muerto en el hospital, víctimas de su idiosincrasia más que de su propia miseria”. Tal vez en estas líneas estuviera aludiendo Vinardell, nuevamente, a Verlaine. El gran poeta maldito no murió en un hospital, pero sí es cierto que muchos así lo creyeron durante largo tiempo: bien porque en sus diez últimos años de vida había ingresado en ellos hasta en veinte ocasiones ${ }^{16}$, bien porque aquellas experiencias en sus "palacios de invierno" lo habían convertido en el raro autor de Mes hôpitaux (1891).

Arturo Vinardell deja atrás sus prejuicios sobre el estilo de vida de Alejandro Sawa y lanza una pregunta cuya respuesta es, adelanta, un misterio que solo los íntimos llegaron a entender: “cómo vivió Sawa en París durante esos tres o cuatro años de bohemia”. Interesa aquí especialmente esa horquilla cronológica señalada, pues resulta llamativo que de toda la estancia parisina de Sawa — 1889 a 1896, si bien con algunas interrupciones - Vinardell cifre en solo tres o cuatro aquellos "años de bohemia". Probablemente esté distinguiendo una segunda etapa del escritor en París: la que principiara al desvincularse de la casa Garnier, esto es, al abandonar cierta estabilidad horaria y pecuniaria para exponerse al vértigo de la más verlainiana y tabernaria bohemia. No en vano, Vinardell había escrito unos párrafos antes, a propósito de aquella renuncia del escritor como redactor del Diccionario: "Nos abandonó Alejandro Sawa, y a partir de aquel momento empezó a recorrer París con sus aires marciales y casi magestuosos [sic] de gran bohemio.” No obstante, cuesta creer que a Vinardell no le constaran, o que no las intuyera, determinadas fórmulas con las que el novelista obtuvo ingresos en aquellos años: colaboraciones en la prensa española y francesa, posibles traducciones y hasta el ejercicio de algunas corresponsalías. Tampoco parecen haber llegado a sus oídos las turbulentas experiencias de Sawa en las mesas de los casinos belgas, sus estrepitosas deudas y

15 En el prólogo a Iluminaciones en la sombra, escribiría Darío: "Un día [Sawa] me mostró un diario, muy animado, muy alegre: - ¡Por fin voy a retornar a París! Ve quién es ministro, un íntimo amigo mío’. Era verdad lo que decía. Pierre Baudin había sido nombrado ministro de ya no recuerdo cuál Gabinete de Loubet, y Pierre Baudin había sido, en efecto, amigo íntimo de Sawa en días de juventud. Pero ¿se acordaría Baudin? ¿Le escribiría Sawa siquiera felicitándole? Ambos son puntos de dudar. El hecho es que Alejandro no volvió a París" (1977: 74). De Pierre Baudin se ocupó Sawa en dos de sus crónicas. La primera fue publicada en el Heraldo de Madrid en 1897, recién nombrado su amigo presidente del Consejo municipal de París. Este texto apareció reproducido o reelaborado en otros medios, en 1902, 1903 y 1904, según apunta Chavarría (Alejandro Sawa 2008: 539, n. 3). La segunda crónica vio la luz en La Lucha en 1904, con Baudin referido como Ministro de Obras Públicas. Amelina Correa Ramón anota la existencia en el archivo de Sawa de una fotografía de Baudin a él dedicada.

16 Así lo documenta el biógrafo Alain Buisine en su Paul Verlaine. Histoire d'un corps. Tomo el dato de Günther Schmigalle (2009). 
los inevitables sablazos a los que aquellas lo abocaran. O nada supo Vinardell de todo ello, o tal vez prefirió contribuir al misterio con su silencio, para amplificar así la leyenda del personaje.

Sea como fuere, el periodista recuerda la última vez que vio a Sawa: "Una mañana de crudo invierno vino a aguardarme a la puerta de la redacción donde yo trabajaba para pedirme un servicio. Le vi pálido y casi astroso y me apresuré a atenderle." Si la memoria del cronista no incurre en errores, y si tratamos de casarla con los datos biográficos de Sawa de que disponemos, hemos de situarnos no antes de la última semana de marzo de 1896; no estrictamente en invierno, pero sí con la fría estación resistiéndose a dejar paso a la primavera. Sabemos, a través de ciertas cartas entre el escritor y su esposa Jeanne Poirier exhumadas por Pura Fernández, que entre enero y marzo de aquel año Sawa residió en Madrid. Buscaba allí un clima más favorable para sus dolencias físicas, al tiempo que preparaba su definitiva instalación en la capital, una vez lograra traerse de París a Jeanne y a la recién nacida Helena. $\mathrm{Su}$ maltrecha salud retrasaría "el encuentro con Jeanne en París, que se produce a finales de marzo, y durante el cual contraen matrimonio" (Pura Fernández 1998, I: 250). La carta XXXI anota, en efecto, la llegada de Sawa a la capital gala en la mañana del lunes 23 de ese mismo mes (Pura Fernández 1998, II: 577). En ella anunciaba a Jeanne su propósito de volver a Spa el siguiente jueves "le plus tard", a probar suerte por enésima vez en la ruleta. Es de suponer que finalmente pospuso esa nueva incursión en el casino belga (hay que esperar al 31 de julio para encontrar una carta fechada desde Spa), que cumplió con su promesa de contraer matrimonio (está documentado el lugar de la celebración, no así la fecha) y que en consecuencia, como sostiene Correa Ramón, "parece ser que la pareja junto con la pequeña Helena se habrían instalado en Barcelona ya en la primavera de ese año 1896” (2008: 202) ${ }^{17}$. El testimonio de Arturo Vinardell vendría a corroborar este traslado, ya que tras haber referido su último encuentro con Sawa, escribe: "A los pocos días me dijeron que había regresado a Madrid pasando por Barcelona, acompañándole en su viaje una hermosa joven que había conocido en París y una linda criaturita de dos o tres años”.

Tres años y casi cinco meses debía tener por entonces aquella niña (la pequeña Helena había venido al mundo el 16 de noviembre de 1892). Vinardell no alcanzó a verla, pero vierte sobre ella una observación que, por humorística o por literaria, resulta impagable: “[su] parecido con Alphonse Daudet era tan grande, que cualquiera hubiese podido tomarla por hija del gran novelista”. Si el comentario llegó hasta él a través de otros o si forma parte de su propia cosecha es algo que probablemente no sabremos nunca. De lo que podemos estar seguros es de que jamás volvería Arturo Vinardell a tener contacto directo con Alejandro Sawa. Todo cuanto pudo saber del sevillano, en el correr de los años, fue que "estaba atravesando miseria en Madrid", además de la pérdida de su visión. Tales tragedias lo mueven a escribir una hermosa línea: “Con alma y vida hubiera yo querido devolver al insigne autor de Noche y Crimen Legal la luz de sus ojos y el relativo bienestar perdidos.”

Una carta de Sawa a su amigo Narciso Díaz Escovar, fechada el 2 de mayo, muestra la dirección de la residencia provisional de la pareja: el número 10 de la calle Gobernador, en Barcelona. Hay que subrayar, por otro lado, que los planes nupciales previstos por Sawa llevaban otro orden cronológico. Según se desprende de una carta del 12 de febrero de 1896, su intención era la de disfrutar primero del viaje de novios en Spa (dejando con la abuela a la pequeña Helena) y casarse en París a la vuelta; o tal vez sucediera así. 
Los recuerdos tocan a su fin. El último párrafo, que comienza con un “¡Pobre Sawa!” casi inevitable ${ }^{18}$, parece reservado a tratar de explicar al personaje. Vierte en él Vinardell dos notas psicológicas que vienen a ser, al fin, el resumen definitivo de una opción de vida conscientemente elegida. La primera es observada a partir de la novela más autobiográfica del bohemio, Declaración de un vencido" ${ }^{19}$. Aunque en sus páginas Sawa había ensayado su doliente autorretrato, el de un hombre -Carlos Alvarado- destruido por una sociedad, Vinardell considera que "en realidad jamás quiso doblegar su altivez innata ante los reveses de la fortuna". La segunda reflexión ahonda en la megalomanía del escritor, señalada aquí como el punto débil que siempre lo acompañó. Lejos de defenestrar a Sawa con este comentario, el catalán aprovecha aquella flaqueza del hombre para elevarlo sobre el resto de sus coetáneos: "Tuvo en vida una debilidad: la de querer aparecer más grande de lo que era con serlo mucho más que otros que figuran inmerecidamente en la cúspide de las letras españolas."

Difícilmente podía escribirse una necrológica sobre Sawa sin volver a la anécdota que mejor y a más altura ha apuntalado su leyenda: el beso que recibiera de Victor Hugo, para honor de una frente que no volvería a ser lavada. Así lo hace Arturo Vinardell, eligiendo como cierre de su semblanza este conocido episodio sobre el que tanto se ha discutido. Recordemos que Rubén Darío, en su prólogo póstumo, había señalado a Luis Bonafoux como el creador de la ficción y el primero en propagarla por escrito. Aquellas líneas del bilioso articulista provocaron una airada carta de Sawa repleta de protestas por las aviesas deformaciones del relato, pero que valieron para que su protagonista confirmara la veracidad del beso del francés ${ }^{20}$. En cualquier caso, Vinardell se esfuerza en demostrar la naturaleza apócrifa de aquel encuentro con el autor de Los miserables. Así, deja claro que se trata de una ficción que, "soberbia, casi altanera", fue construida por el propio Sawa y difundida por este entre sus amigos. Para demostrar la imposibilidad de aquel beso, el cronista destina una nota a pie de página en la que recuerda el año del fallecimiento de Hugo, 1885, y el año en que Sawa llegó a París, 1889. Ya se ha apuntado en este trabajo la posibilidad de que Sawa realizara un primer viaje a la ciudad del Sena antes de mayo de 1885, por lo que quizá no hubo tal invención por parte del sevillano. Este extremo, evidentemente, no fue conocido por Vinardell ${ }^{21}$.

18 Exclamatio propia de infinidad de textos elegiacos, no faltó tampoco en las páginas que motivó la muerte del bohemio; desde el “¡Pobre Sawa!” que lanza Gómez de la Serna en unas líneas ya citadas, hasta el póstumo “Poor Alex!” que Darío dejó en su prólogo a Iluminaciones en la sombra, por citar solo dos casos.

19 Vinardell escribe "Confesión de un vencido".

20 El artículo de Bonafoux al que aludía Darío era el célebre "Sawa, su perro y su pipa". En la reproducción que conoció este texto en Heraldo de Madrid (8-III-1909), con el título de "Alejandro Sawa” y seguido de la vehemente contestación del propio Sawa, el autor señaló en El Español su primer desvelo, más de veinte años atrás. Desafortunadamente no ha sido posible dar con ningún ejemplar de este semanario que fundara en su día el vitriólico periodista, cuyos números se publicaron entre 1882 y 1887. Tanto Phillips (que señala otra reproducción del artículo y de su respuesta, esta vez en el Heraldo de París, el uno de marzo de 1902) como Correa Ramón, además de otros estudiosos, han venido citando siempre el texto de Bonafoux desde las páginas del Heraldo de Madrid. Quiero dar noticia en esta nota a pie de una reproducción más de "Sawa, su perro y su pipa", que parece haber pasado desapercibida: la publicada en Madrid por La Ilustración de España. Periódico Ilustrado de Literatura, Ciencias, Artes y Modas, el 22 de enero de 1888.

21 Para todo lo relacionado con el beso de Hugo a Sawa, véanse Phillips (1976: 16-20) y Correa Ramón (2008: 71-76 y 2012: 3-17). 
Como puede derivarse de cuanto aquí se ha analizado, esta “crónica de París" contribuye, sin duda, a un mayor conocimiento de la figura de Alejandro Sawa, fundamentalmente en lo tocante a sus años en la Ville lumière. Su interés pasa, no ya por el testimonio de primera mano que en sí mismo constituye, sino por la concurrencia en él de dos perspectivas. La primera, la de quien escribe desde el hondo conocimiento del contexto que conformó a aquel Sawa retratado: París. La segunda - y en esto se diferencia por completo de testimonios como los de Gómez Carrillo o Rubén Darío-, la de un hombre de tan distinto temperamento al del bohemio; libre así del contagioso culto al genio o de pueriles admiraciones heredadas, a los que fueron tan dados los panegiristas.

La página de Vinardell ayuda a esclarecer algunos pasajes de la biografía de Sawa: niega su presencia en la Exposición Universal de 1889 (sobre la que llegó a escribir en calidad de visitante); abre necesariamente la puerta a la consideración de dos estancias - y no una, como hasta ahora ha venido sosteniéndose- previas a su instalación en París aquel año; por último, acota con más precisión la fecha del regreso definitivo de Sawa, su esposa y su hija a España. Por lo demás, Vinardell ofrece un retrato que se esfuerza en separar al hombre del escritor. En la primera de las esferas hay cabida para el elogio personal, pero también para una implacable crítica moral sobre los modos bohemios de Sawa; en la segunda de ellas, no deja de reconocerse el talento literario del andaluz, a quien dos novelas nombradas por Vinardell —Noche y Crimen legal - le bastan para ser señalado como "insigne autor".

Compuesta desde la urgencia propia de las notas necrológicas, los párrafos del cronista trazan una silueta que no evita la repetición de tópicos sobre el singular escritor, pero donde al menos uno sí quiere ser claramente derruido: el que concierne al mítico beso de Victor Hugo. El hecho de que Vinardell destine el final de su texto a demostrar la falsedad de tal leyenda, su empeño último en señalarla como pura invención del sevillano, parecen responder a un propósito deliberado, no exento de cierta complacencia moral: pintar el retrato de una figura fraudulenta, el de alguien que no existió en la realidad, el del absurdo personaje inventado por sí mismo; en definitiva, la imagen del escritor al que su propia ficción lo acaba derrotando, no sin haberlo hecho antes su altivez y sus delirios de grandeza.

TRANSCRIPCIÓN ÍNTEGRA DEL ARTÍCULO

DE ARTURO VINARDELL ROIG (“DARWIN")

\author{
CRÓNICA DE PARÍS \\ Los grandes bohemios. Alejandro Sawa
}

\begin{abstract}
A pesar de los malísimos recuerdos que dejó en mí al desaparecer súbitamente de París, Alejandro Sawa, con quien estuve rozándome íntimamente casi a diario durante los cortos años de su permanencia en esta Capital, declaro con toda la sinceridad de mi alma noble que la noticia de su muerte llegada hasta mí a los pocos meses de conocer su ceguera, me ha entristecido hondamente. Quiero dar al olvido la ingratitud con que pagó, en un momento de aberración mental, los modestos servicios que mi amistad pudo ofrecerle, y no voy a acordarme
\end{abstract}


sino del gran bohemio, del escritor de talento que al pasar por París dejó marcadas sus huellas, cosa que no es dable aquí sino a los audaces o a los escogidos.

Vino Sawa a París cuando acababa de cerrar sus puertas la brillante Exposición universal de 1889, pero quedaban todavía las secuelas de aquel certamen inolvidable, y entre todas, quedaban en permanencia, como sello definitivo de aquel prodigioso esfuerzo de la actividad humana, el Palacio de las Máquinas, soberbio por su audacia arquitectónica y, sobre todo, la colosal Torre Eiffel, símbolo acabado de la metalurgia triunfante, erguida en medio del campo de Marte como el dedo misterioso del Genio señalando a la urbe inmensa la ruta de sus grandes destinos. Si otra cosa no hubiese tenido París, esto solo era ya bastante para atraer a Sawa, que nunca supo profesar otro culto que el culto a lo grandioso y a lo sublime.

Le conocí, como a Gómez Carrillo y como a tantos otros, en la redacción del Diccionario enciclopédico de la Lengua española que a la sazón estaba preparando la casa editorial Garnier hermanos. Pero de allí salió a escape Alejandro Sawa. Sus aspiraciones, que apuntaban más alto, su espíritu independiente, su temperamento errabundo no podían armonizarse con aquella clase de trabajo metódico y serio, ni con aquella férrea disciplina que nos obligaba a todos a determinadas horas de presencia y a una suma de labor monótona y fastidiosa, impropia de quienes, como Sawa, sentíanse con fuerzas para volar por otras regiones y abarcar otros horizontes. Nos abandonó Alejando Sawa, y a partir de aquel momento empezó a recorrer París con sus aires marciales y casi magestuosos [sic] de gran bohemio. Le recuerdo todavía como si lo viera. De regular estatura, arrogante en sus maneras sin ser altivo, con su poblada barba negra de moruno aspecto, ostentando en su opulenta cabeza una abundosa melena semejando una cimera, era Sawa un tipo francamente español, simpático en extremo. Alguien ha dicho - y es cierto - que Sawa tenía un asombroso parecido con Alphonse Daudet, con su cara de Cristo resucitado. Con talento y con esa atrayente fisonomía no es extraño que, en poco tiempo, Sawa hubiese conquistado la amistad de los intelectuales franceses de aquel momento histórico. Gracias a ella pudo seguir viviendo en París durante un cortísimo número de años...

Pero también, gracias a ella, o mejor dicho, por culpa de ella, de esa amistad íntima que hubo de ligarle con algunos personajes de la época, el pobre Alejandro Sawa llegó a pervertirse en sus costumbres y casi, casi a rebajarse. Amplio y elocuente en sus palabras, elegante en su decir y en sus maneras, vile yo muchas veces a la altura de Paul Verlaine, su ilustre y querido amigo a quien tuteaba, cuando este, en sus momentos de furor alcohólico, arrastraba el manto de armiño de la santa poesía por el subsuelo de ciertas tabernas a la moda o bajo las mesas del café François, el punto de cita y sanedrín de toda la bohemia trashumante de aquel París intelectual, que había consagrado a Verlaine como su Dios y a Moreas [sic] como su profeta. Allí conoció a toda esa pléyade de jóvenes más o menos ilustres, algunos de los cuales, más prácticos o más previsores que todos sus compañeros, supieron abandonar oportunamente aquella vida insípida de bacanal hedionda para lanzarse al estudio provechoso del arte de gobernar, donde al fin hallaron ancho camino para el ejercicio de su talento y el logro de sus ambiciones. Recuerdo, entre otros, a Pierre Baudin gran amigo de Sawa, a quien en pocos años, vi conquistar los sitios envidiables de presidente del Consejo municipal de París y de ministro de Obras públicas, mientras que la mayor parte de sus camaradas se han estado royendo las uñas de pobreza o de fastidio, sin contar los que han muerto en el hospital, víctimas de su idiosincrasia más que de su propia miseria.

Que cómo vivió Sawa en París durante esos tres o cuatro años de bohemia, se preguntará acaso el que no conozca de su vida sino los ditirambos que le han prodigado después de muerto los que siempre le habían hincado el diente por ruin envidia. Es un misterio que se ha llevado a la tumba y que solo conocen algunos - pocos — que lo trataron íntimamente en esta capital. Una mañana de crudo invierno vino a aguardarme a la puerta de la redacción donde yo trabajaba para pedirme un servicio. Le vi pálido y casi astroso y me apresuré a atenderle.

A los pocos días me dijeron que había regresado a Madrid pasando por Barcelona, acompañándole en su viaje una hermosa joven que había conocido en París y una linda 
criaturita de dos o tres años cuyo parecido con Alphonse Daudet era tan grande, que cualquiera hubiese podido tomarla por hija del gran novelista. Jamás he vuelto a saber nada directamente de Sawa. Supe que estaba atravesando miseria en Madrid y que se había vuelto ciego. Con alma y vida hubiera yo querido devolver al insigne autor de Noche y Crimen Legal la luz de sus ojos y el relativo bienestar perdidos.

¡Pobre Sawa! Hizo su propio retrato en la Confesión de un vencido; pero en realidad jamás quiso doblegar su altivez innata ante los reveses de la fortuna. Tuvo en vida una debilidad: la de querer aparecer más grande de lo que era con serlo mucho más que otros que figuran inmerecidamente en la cúspide de las letras españolas. Ha muerto dejando una ficción suya, soberbia, casi altanera, que le pinta de cuerpo entero; la da haber dicho a sus amigos, que no se cuidaron de comprobar fechas, que Victor Hugo (1) le había dado un ósculo en la frente y que, desde entonces él, Alejandro Sawa, no había vuelto a lavársela para no borrar la huella de aquella consagración sublime del Maestro.

Darwin

París, Marzo de 1900 [sic].

(1) Victor Hugo murió en 1885, Sawa llegó a París a fines de 1889.

\section{OBRAS CITADAS}

Anónimo. 1909. “Alejandro Sawa”. El Liberal (3-III-1909).

Baroja, Pío. 1982. El árbol de la ciencia. Madrid: Alianza Editorial.

Bello, Luis. 1909. El Mundo (3-III-1909).

Clara, Josep. 1987. "El delicte periodístic d'Artur Vinardell”. Revista de Girona 121: 75-79.

Correa Ramón, Amelina. 2008. Alejandro Sawa. Luces de bohemia. Sevilla: Fundación José Manuel Lara.

2012. "Alejandro Sawa y la leyenda francesa: de Victor Hugo a Verlaine". Les

Cahiers du Litoral (Unité de Recherche sur l'histoire, les langues, les littératures, et l'interculturel/Centre d'Études et de Recherche sur les Civilisations et les Littératures Européennes, Boulogne sur mer) I. 14: 3-17.

Dicenta, Joaquín. 1897. "De mi bohemia". Prólogo a Fuente, Ricardo. 1897. De un periodista. Madrid: Romero Impresor. 9-16.

Fernández, Pura. 1998. "El epistolario inédito de Alejandro Sawa a su esposa Jeanne Poirer (1892-1898) (I)”. Revista de Literatura LX. 119: 243-262.

. "El epistolario inédito de Alejandro Sawa a su esposa Jeanne Poirer (1892-1898) (II)". Revista de Literatura LX. 120: 559-588.

Fischer Hubert, Denise. 1994. El libro español en París a comienzos del siglo XX. Escritores y traductores. Tarragona: Universidad Rovira i Virgili (tesis doctoral con depósito legal T 967-2014).

Frollo, Claudio [seud. López, Ernesto]. 1899. “Alejandro Sawa”. Heraldo de Madrid (22-I1899).

Gallén, Enric y Nosell, Dan. 2011. Guimerà i el Premi Nobel. Història d'una candidatura. Lleida: Punctum-Grup d'Estudis de la Literatura del Vuit-cents.

Gómez Carrillo, Enrique. 1892. Esquisses. Siluetas de escritores y artistas. Madrid: Imprenta de la Vda. de Hernando y Cía. . 1899. La Vida Literaria (4-II-1899). 
1900. Sensaciones de París y de Madrid. París: Garnier Hermanos.

Gómez de la Serna, Ramón. 1909. Prometeo (4-II-1909).

López Lapuya, Isidoro. 2001. La bohemia española en París a fines del siglo pasado. Desfile anecdótico de políticos, escritores, artistas, prospectores de negocios, buscavidas y desventurados. Sevilla: Renacimiento.

Palomero, Antonio. 1899. El Nuevo País (28-I-1899).

París, Luis. S.a. [h. 1888]. Gente nueva. Madrid: Imp. Popular.

Pérez Arroyo, Gregorio. 1901. "Un poeta muerto". El País (25-VIII-1901).

Phillips, Allen W. 1976. Alejandro Sawa. Mito y realidad. Madrid: Turner.

Pompey, Francisco. 1972. Recuerdos de un pintor que escribe. Semblanzas de grandes figuras. Madrid: Artes Gráficas Iberoamericanas.

San Germán Ocaña, José. 1909. "Iconografía literaria”. Nuevo Mundo (8-III-1909).

Sawa, Alejandro. 1977. Iluminaciones en la sombra. Edición, estudio y notas Iris M. Zavala. Madrid: Alhambra.

. 2008. Crónicas de la bohemia. Edición, introducción y notas de Emilio Chavarría. Madrid: Veintisieteletra.

Schmigalle, Günther. 2009. "Rubén Darío y Paul Verlaine: Una nueva lectura de su desencuentro en 1893”. Istmo: Revista Virtual de Estudios Literarios y Culturales Centroamericanos 19.

Valle-Inclán, Ramón del. 1991. Luces de bohemia. Ed. Alonso Zamora Vicente. Madrid: Espasa-Calpe.

Vinardell Roig, Arturo. 1902. España en París. Barcelona: Antonio López. . 1909. "Los grandes bohemios. Alejandro Sawa”. Diario de Tenerife (6-IV-1909). 